\title{
ORIGINAL ARTICLE \\ Mucosal immune responses during court training in elite tetraplegic athletes
}

\author{
CA Leicht, NC Bishop and VL Goosey-Tolfrey
}

\begin{abstract}
Study design: Experimental study.
Objectives: To examine salivary secretory immunoglobulin $A$ (slgA) responses and $\alpha$-amylase activity during court training in highly trained tetraplegic athletes.

Setting: Loughborough, UK.

Methods: Seven highly trained wheelchair rugby athletes with tetraplegia performed two separate wheelchair rugby court training sessions, lasting 23 and $41.5 \mathrm{~min}$, respectively, with either an aerobic or an interval focus. Timed, unstimulated saliva samples were obtained pre, post and 30 min post exercise and analysed for slgA and $\alpha$-amylase. Furthermore, blood lactate concentration and rating of perceived exertion (RPE) immediately after training were measured.

Results: $\quad$ slgA secretion rate and $\alpha$-amylase were unaffected by exercise during both sessions. However, the increases of slgA concentration ( $30 \mathrm{~min}$ post exercise: $+67 \pm 29 \%$ ) during the aerobic session were accompanied by decreases in saliva flow rate $(-35 \pm 22 \%)$. Athletes' physiological responses to exercise document the highly strenuous nature of the sessions, with blood lactate concentrations reaching $8.1 \pm 1.0$ and $8.7 \pm 1.6 \mathrm{mmolI}^{-1}$ and RPE reaching $18(17,18)$ and $16(15,17)$ for the aerobic and the interval session, respectively.

Conclusion: Acute bouts of highly strenuous exercise do not have negative impacts on the mucosal immune response in tetraplegic athletes, nor do they influence the production of $\alpha$-amylase, a marker of sympathetic nervous activity. This contrasts responses previously observed in able-bodied athletes. The disruption of the sympathetic nervous system may prevent the downregulation of slgA secretion rate following intense exercise, which is a response previously observed in able-bodied athletes.
\end{abstract}

Spinal Cord (2012) 50, 760-765; doi:10.1038/sc.2012.47; published online 8 May 2012

Keywords: oral immune function; wheelchair rugby; salivary immunoglobulin A; amylase; autonomic innervation

\section{INTRODUCTION}

Salivary secretory immunoglobulin A (sIgA) is the predominant immunoglobulin in saliva and other mucosal secretions. It has been described as 'the first line of defence' against pathogens and antigens presented at the mucosa, such as viruses responsible for the common cold. ${ }^{1,2}$ Further, sIgA has been suggested to be a useful clinical biomarker to predict the incidence of upper respiratory tract infection, ${ }^{3}$ as decreased levels of sIgA have been associated with subsequent episodes of this ailment. ${ }^{3,4}$ Secretion of sIgA can be modified by both parasympathetic and sympathetic nerve stimulation. ${ }^{5}$ Intensive exercise is associated with enhanced sympathetic nervous system activity and has therefore the potential to modify secretion of saliva and its constituent proteins. ${ }^{1}$ Indeed, decreased sIgA secretion rates have been reported following strenuous exercise in able-bodied individuals. ${ }^{6-8}$

Tetraplegic individuals represent a model with no centrally mediated sympathetic nervous control, ${ }^{9}$ as centrally mediated sympathetic stimuli do not activate the decentralised part below the level of lesion. ${ }^{10}$ It must further be noted that the innervation of the salivary glands in tetraplegic individuals is also disrupted, as it originates from the upper thoracic segments. ${ }^{5}$ Some of these changes affect the immune response of this population and ultimately, its health. For instance, certain parameters (for example, natural killer cell number, cytotoxicity) of innate immunity are depressed in the spinal cord injured population in resting conditions, ${ }^{11}$ and a number of comorbidities have been associated with the impaired autonomic, ${ }^{9}$ immune $^{12}$ and/or respiratory function. ${ }^{13}$ Given the above-mentioned effects of sympathetic activation on $\operatorname{sig} \mathrm{A}$, the decreased sympathetic outflow in tetraplegic individuals ${ }^{14,15}$ can result in an altered immune response following intense exercise when compared with populations with intact sympathetic innervation. ${ }^{16}$ We believe that extending the insights of laboratory testing into a more applied, field-based environment will increase the practical value for the exercising individual. The data obtained could hence serve as a base of health promotion and monitoring in this specific athletic population. Looking beyond the research context, the use of salivary markers, with the practical advantage of easy and non-invasive data collection, may help providing feedback for athletes and coaches.

Therefore, the purpose of this investigation was to explore the impacts of highly strenuous court training sessions on the mucosal immune response in tetraplegic athletes. Because of the nature of their disability with a disruption of autonomic nerve pathways, we hypothesise that sIgA will not be downregulated as a result of exercise-induced changes of sympathetic activity. 


\section{MATERIALS AND METHODS}

\section{Participants}

Seven male highly trained tetraplegic wheelchair rugby athletes with motor and sensory complete lesions volunteered to participate in this study. All participants regularly attended structured training sessions with the Great Britain national team under the supervision of appointed strength and conditioning coaches; participant 3 performed the sport on a national level, all other participants on an international level. A weekly training volume of at least $10 \mathrm{~h}$ was required for inclusion in this study. Prior to the study, all participants were classified for wheelchair rugby functional class according to the International Wheelchair Rugby Federation Classification system; ${ }^{17}$ a summary of their physical and sport characteristics is presented in Table 1.

\section{Experimental design}

Participants were monitored during two regular court training sessions, designed and supervised by the same coach, which were separated by $7-14$ days for all athletes (Figure 1). As the sessions were part of the participants' yearly training schedule, the investigators could not influence the order of the sessions (five athletes completed the aerobic training session first). Both sessions took place at the same indoor location and started at 1100 hours, and participants were advised to consume the same breakfast on both days of testing. Before the sessions, participants provided written informed consent and completed separate health, training and disability questionnaires. They were then weighed to the nearest $0.1 \mathrm{~kg}$ with a wheelchair double beam scale (300 series, Marsden, London, UK). Training sessions were performed in the participants' competition wheelchair. Both sessions were preceded by a 20 -min warm-up period, which included easy pushing, agility practice, short sprints and stretching.

Session 1 ('aerobic' session) consisted of five blocks, each separated by $2 \mathrm{~min}$ of passive recovery. Each block consisted of $3 \mathrm{~min}$ of forward pushing on a lap, including a downhill and an uphill ramp, straight sections and slalom around cones. Athletes were required to cover as much distance as possible during each block. The whole training session lasted $23 \mathrm{~min}$, whereas the active part of the session accounted for $15 \mathrm{~min}$.

Session 2 ('interval' session) consisted of three blocks, each separated by $5 \mathrm{~min}$ of passive recovery. Each block consisted of six bouts of $30 \mathrm{~s}$, where athletes were required to perform forward and back pushing between lines $2-3 \mathrm{~m}$ apart for the first $15 \mathrm{~s}$, followed by a sprint during the last $15 \mathrm{~s}$, all at maximum effort. Bouts were repeated after $90 \mathrm{~s}$ of rest, meaning that the whole training session lasted $41.5 \mathrm{~min}$, whereas the active part of the session accounted for $9 \mathrm{~min}$.

\section{Data collection}

Timed, unstimulated saliva samples were collected into sterile plastic containers before, immediately after and $30 \mathrm{~min}$ post exercise. For this, participants rinsed their mouth with water and sat still with their head slightly tilted forward with minimal orofacial movement. Participants were allowed to consume drinks ad libitum apart from 5 min prior to each collection. Before and immediately after the training session, small capillary blood samples were obtained from the earlobe to measure blood lactate concentrations using a lactate analyser (Lactate Pro, Arkray, Kyoto, Japan), which was calibrated before each session according to the manufacturer's guidelines.

Further, participants were asked to indicate their overall RPE (rating of perceived exertion) using a scale ranging from 6 to $20^{18}$ at the end of the sessions. Heart rate was continuously recorded using a heart rate monitor (Polar Team System, Polar, Kempele, Finland), and the highest average 5-s interval achieved during each session was defined as $\mathrm{HR}_{\text {peak }}$. Finally, a data $\operatorname{logger}{ }^{19}$ was fitted to the wheelchairs to collect distance data during each court training session.

\section{Analytical methods}

Saliva samples were stored on ice immediately following collection and stored at $-20{ }^{\circ} \mathrm{C}$ upon return to the laboratory. For analysis, samples were defrosted and weighed to the nearest $10 \mathrm{mg}$. Saliva volume was estimated assuming saliva density to be $1 \mathrm{~g} \mathrm{ml}^{-1}$ (ref. 20) and saliva flow rate calculated from saliva volume and collection time. sIgA concentration and salivary $\alpha$-amylase activity
Table 1 Participants' characteristics

\begin{tabular}{|c|c|c|c|c|c|c|}
\hline Participant & $\begin{array}{c}\text { Age } \\
\text { (years) }\end{array}$ & $\begin{array}{c}\text { Lesion } \\
\text { level }\end{array}$ & $\begin{array}{l}\text { Body } \\
\text { mass } \\
(\mathrm{kg})\end{array}$ & $\begin{array}{c}\text { Elite sport } \\
\text { experience } \\
\text { (years) }\end{array}$ & $\begin{array}{l}\text { Rugby } \\
\text { classi- } \\
\text { fication }\end{array}$ & $\begin{array}{c}\text { Training } \\
\text { volume } \\
\left(\text { h week }^{-1} \text { ) }\right.\end{array}$ \\
\hline 1 & 28 & C6 & 56.2 & 8.0 & 0.5 & 13.5 \\
\hline 2 & 39 & C5/6 & 64.4 & 6.0 & 1.0 & 10.0 \\
\hline 3 & 20 & C7 & 65.4 & 0.3 & 2.0 & 16.0 \\
\hline 4 & 32 & C6/7 & 64.2 & 8.0 & 2.0 & 13.5 \\
\hline 5 & 30 & $\mathrm{C} 6 / 7$ & 69.8 & 6.0 & 2.5 & 13.5 \\
\hline 6 & 32 & C6/7 & 94.8 & 8.0 & 2.5 & 15.0 \\
\hline 7 & 30 & $\mathrm{C} 6 / 7$ & 68.9 & 5.0 & 2.5 & 19.0 \\
\hline Mean & 30 & NA & 69.1 & 5.9 & NA & 14.4 \\
\hline s.d. & 6 & NA & 12.2 & 2.8 & NA & 2.8 \\
\hline
\end{tabular}

Abbreviation: NA, not applicable.

Rugby classification according to the international wheelchair rugby federation. ${ }^{17}$

moderate intensity $\square$ maximum intensity $\square$ passive recovery

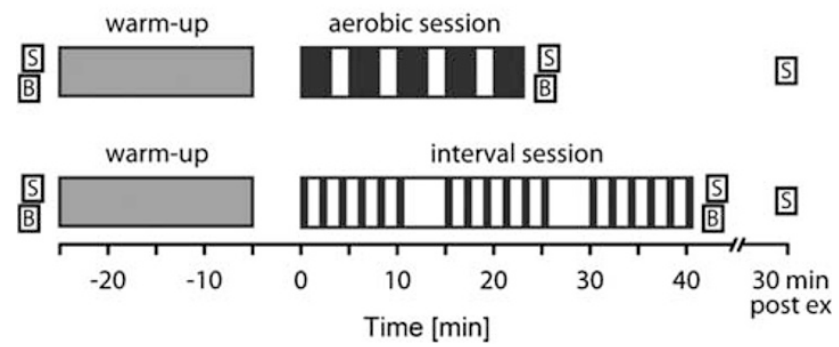

Figure 1 Design of the two court training sessions. S, saliva collection; $\mathrm{B}$, capillary blood collection; ex, exercise.

were then determined; details of these methods have been described previously. ${ }^{16}$ All samples from the same participant were analysed in duplicate on one microplate. The coefficient of variation of the methods based on analyses of these duplicate samples was $1.7 \pm 1.4 \%$ for sIgA and $1.6 \pm 1.2 \%$ for $\alpha$-amylase.

Osmolality was determined using a calibrated cryoscopic osmometer (Osmomat 030, Genotec, Berlin, Germany). Samples were analysed in duplicate, the coefficient of variation was $1.1 \pm 1.3 \%$.

\section{Data processing and statistical analyses}

The SPSS 19 statistical package (SPSS Inc., Chicago, IL, USA) was used for all statistical analyses. Sample size calculation was based on previous unpublished pilot data of relative increases in sIgA secretion rates $(22 \pm 16 \%)$ comparing pre and post values of an intensive training session in elite paraplegic athletes. Using GPower 3.1.2 (Heinrich Heine University, Duesseldorf, Germany), we calculated we would need seven participants to detect a similar change in sIgA secretion rate, with an effect size of $1.38,90 \%$ power and an $\alpha$ of $5 \%$.

All salivary responses were expressed as absolute values, and, to account for differences of pre exercise values, post and $30 \mathrm{~min}$ post exercise data were expressed as a percentage of the pre exercise value (from here on referred to as 'percentage data'). sIgA responses were expressed as concentration, secretion rate and sIgA concentration ratio to osmolality (sIgA:osmolality).

Normality was checked with the Shapiro Wilk test. Means and s.d. were computed for normally distributed variables, medians and quartiles for all other variables. To normalise data, a logarithmic transformation was applied to absolute and percentage saliva flow rate data, and a square root transformation was applied to HR and percentage sIgA data. A two-way (time $\times$ exercise type) analysis of variance (ANOVA) was applied to normally distributed salivary percentage data, Friedman and Wilcoxon tests for non-normally distributed percentage and RPE data. Paired t-tests were performed to compare absolute salivary pre exercise values, distance data, $\mathrm{HR}_{\text {peak }}$ and $\mathrm{BLa}_{\text {peak }}$ between the two court training sessions. To examine the effects of saliva flow rate on 
sIgA concentration, a two-way ANOVA (time $\times$ parameter) was performed on log-transformed percentage post and $30 \mathrm{~min}$ post data of the aerobic session. For all comparisons where the assumption of sphericity was violated, a Greenhouse Geisser correction was applied. Statistical significance for all analyses was accepted at $P<0.05$.

We certify that all applicable institutional and governmental regulations concerning the ethical use of human volunteers were followed during the course of this research.

\section{RESULTS}

As a result of the court training sessions, a time $\times$ exercise interaction in sIgA concentration was found, indicating a greater increase in $\operatorname{sgA}$

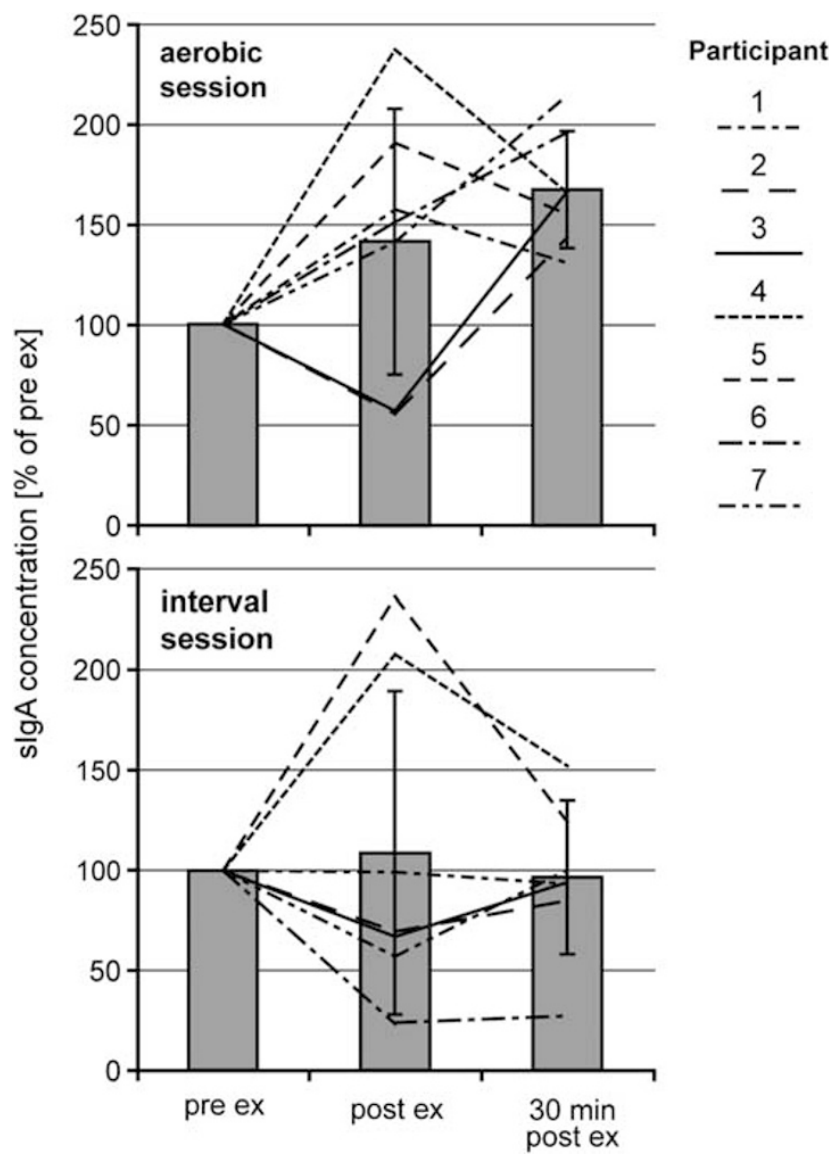

Figure 2 Changes in slgA concentration as a percentage from pre exercise $(\mathrm{ex})$ during court training in wheelchair rugby. Time $\times$ exercise interaction $(P=0.03)$. concentration post and $30 \mathrm{~min}$ post exercise in the aerobic session (Figure 2, $P=0.03$ ). However, the increases of sIgA concentration during the aerobic session were accompanied by decreases in saliva flow rate $(P<0.001)$. Therefore, sIgA secretion rate and sIgA:osmolality were unaffected by exercise $(P=0.13$ and 0.48 , respectively) and time of measurement $(P=0.98$ and 0.57 , respectively). $\alpha$-amylase activity was not affected by any exercise type $(P>0.87$, Table 2$)$. Furthermore, saliva did not differ in osmolality between training sessions $(P=0.42)$ and time points $(P=0.16$; aerobic-pre: $45 \pm 9$, post: $54 \pm 21,30 \mathrm{~min}$ post: $56 \pm 11$; interval-pre: $53 \pm 11$, post: $62 \pm 16,30 \mathrm{~min}$ post: $52 \pm 7 \mathrm{mosmol} \mathrm{kg}^{-1}$ ).

Both court training sessions resulted in substantial elevations of markers associated with physical exertion in all athletes (Table 3). Athletes covered $4155 \pm 483 \mathrm{~m}$ and $3754 \pm 331 \mathrm{~m}$ in the aerobic and the interval session, respectively $(P=0.02)$. Finally, $\mathrm{HR}_{\text {peak }}$ did not differ between court training sessions $(P=0.23$, Table 3$)$.

\section{DISCUSSION}

To our knowledge, this is the first study to demonstrate the effects of field-based training sessions on the mucosal immune function in a cohort of highly trained tetraplegic wheelchair athletes. In line with our hypothesis, the main findings are that acute bouts of highly strenuous exercise do not have negative impacts on the sIgA metabolism in tetraplegic athletes, nor do they influence the production of $\alpha$-amylase, a marker of sympathetic nervous activity. Further, despite the nature of a tetraplegia, which results in profound active muscle mass loss, remarkably high $\mathrm{BLa}_{\text {peak }}$ were measured during both training sessions.

It is commonly accepted that the sympathetic nervous system may at least partly be responsible for the changes in salivary markers, such as sIgA and $\alpha$-amylase. ${ }^{1,21}$ In able-bodied individuals, intense exercise typically results in a rise of catecholamines, which correlates with a rise in $\alpha$-amylase. ${ }^{22}$ Furthermore, depressions in $\operatorname{sgA} A^{6,8}$ and saliva flow rate ${ }^{23}$ have been observed following this type of exercise. Therefore, the absence of significant alterations in sIgA and $\alpha$-amylase in tetraplegic athletes underpins that a functional sympathetic drive has an influence on governing these responses. In line with this, it has been suggested previously that sympathoadrenal activity is responsible for a normal natural killer cell response to exercise, which is blunted in tetraplegic athletes as well. ${ }^{24}$

However, it must be noted that saliva flow rate was decreased (with a concomitant increase in sIgA concentration) in the aerobic session of the present study. Although it has been suggested that increases in sIgA concentration can be caused by changing hydration status, ${ }^{25}$ we do not believe that this was the case in the present study: saliva osmolality, a marker of hydration status, ${ }^{26}$ did not change throughout

Table 2 Salivary responses during wheelchair rugby court training

\begin{tabular}{|c|c|c|c|c|c|c|}
\hline \multirow[t]{2}{*}{ Parameter } & \multicolumn{3}{|c|}{ Aerobic session } & \multicolumn{3}{|c|}{ Interval session } \\
\hline & pre ex & post ex & $30 \min$ post ex & pre ex & post ex & 30 min post ex \\
\hline slgA concentration ( $\mu \mathrm{g} \mathrm{ml}^{-1}$ ) & $84 \pm 23^{*}$ & $118 \pm 56$ & $137 \pm 34$ & $142 \pm 58$ & $127 \pm 65$ & $123 \pm 46$ \\
\hline slgA secretion rate $\left(\mu \mathrm{g} \mathrm{min}^{-1}\right)$ & $53 \pm 26$ & $57 \pm 35$ & $53 \pm 24$ & $68 \pm 37$ & $47 \pm 16$ & $50 \pm 16$ \\
\hline$\alpha$-amylase activity $\left(\mathrm{U} \mathrm{ml}^{-1}\right)$ & $\begin{array}{c}305 \\
(274,318)\end{array}$ & $\begin{array}{c}310 \\
(141,333)\end{array}$ & $\begin{array}{c}258 \\
(209,438)\end{array}$ & $\begin{array}{c}364 \\
(327,438)\end{array}$ & $\begin{array}{c}363 \\
(149,490)\end{array}$ & $\begin{array}{c}248 \\
(207,614)\end{array}$ \\
\hline Saliva flow rate $\left(\mathrm{ml} \mathrm{min}^{-1}\right)$ & $\begin{array}{c}0.65^{*} \\
(0.48,0.71)\end{array}$ & $\begin{array}{c}0.42 \\
(0.39,0.59)\end{array}$ & $\begin{array}{c}0.36 \\
(0.33,0.44)\end{array}$ & $\begin{array}{c}0.46 \\
(0.27,0.66)\end{array}$ & $\begin{array}{c}0.32 \\
(0.26,0.62)\end{array}$ & $\begin{array}{c}0.40 \\
(0.34,0.64)\end{array}$ \\
\hline
\end{tabular}

Abbreviations: ex, exercise; slgA, secretory immunoglobulin A.

slgA data are presented as mean \pm s.d., $\alpha$-amylase activity and saliva flow rate data as median (quartiles).

*Significant difference between aerobic and interval session, at $P<0.05$ level. 
Table 3 Physiological data during court training in wheelchair rugby

\begin{tabular}{|c|c|c|c|c|c|c|}
\hline \multirow[t]{2}{*}{ Participant } & \multicolumn{3}{|c|}{ Aerobic session } & \multicolumn{3}{|c|}{ Interval session } \\
\hline & $H R_{\text {peak }}\left(\right.$ beats min $^{-1}$ ) & $B L a_{\text {peak }}\left(\mathrm{mmol} \mathrm{I}^{-1}\right)$ & $R P E$ & $H R_{\text {peak }}\left(\right.$ beats min $^{-1}$ ) & $B L a_{\text {peak }}\left(\mathrm{mmol}^{-1}\right)$ & $R P E$ \\
\hline 1 & 113 & 7.2 & 17 & 126 & 7.7 & 13 \\
\hline 2 & 135 & 8.4 & 18 & 150 & 11.2 & 16 \\
\hline 3 & 125 & 8.9 & 20 & 128 & 6.9 & 15 \\
\hline 4 & no data & 8.0 & 18 & 139 & 14.3 & 16 \\
\hline 5 & 174 & 9.2 & 17 & 174 & 7.8 & 17 \\
\hline 6 & 117 & 7.9 & 18 & 145 & 9.1 & 15 \\
\hline 7 & 151 & 6.7 & 18 & 138 & 9.6 & 18 \\
\hline Mean/median & 136 & 8.1 & $18^{*}$ & 144 & 8.7 & 16 \\
\hline s.d./quartiles & 23 & 1.0 & 17,18 & 18 & 1.6 & 15,17 \\
\hline
\end{tabular}

Abbreviations: BLa, blood lactate concentration; HR, heart rate; RPE, rating of perceived exertion.

$\mathrm{HR}$ and BLa data are presented as mean and s.d., RPE data as median and quartiles.

* Significant difference between sessions, at $P<0.05$ level.

the sessions. It seems that athletes maintained their hydration status by consuming drinks ad libitum (which is common procedure during training). Therefore, the decreases in saliva flow rate may be attributed to changes in sympathetic activation ${ }^{1}$ rather than dehydration, suggesting the potential of exercise-induced activation of the sympathetic nervous system despite a central lesion. This gains further support as the participants perceived the aerobic session as more strenuous, suggesting a higher potential of sympathetic activity when compared with the interval session. Because of the nature of their disability, abolishing central sympathetic signals to reach effector organs, a mechanism that could still be functional in tetraplegic individuals is sympathetic reflex activity, which we propose as a mechanism potentially being responsible for decreasing saliva flow rate. The suggestion of a remaining, but qualitatively altered sympathetic function gain further support by research observing increased epinephrine and norepinephrine levels in tetraplegic individuals as a result of bladder stimulation ${ }^{27}$ or electrically stimulated cycle exercise. ${ }^{28}$ It has therefore been proposed earlier that sympathetic reflex activity, driven by afferent signals from mechanoreceptors ${ }^{29}$ or muscle acidosis, ${ }^{30}$ is a potential mechanism still functional in tetraplegic individuals. Moreover, a hyperresponsiveness of $\alpha$-adrenoreceptors in tetraplegic individuals ${ }^{31}$ may further compensate for some of the lack of the centrally mediated neural drive. However, it must be appreciated that withdrawal of parasympathetic activity can also cause decreases in saliva flow rate. ${ }^{1}$ Therefore, no definite conclusions about the effect of sympathetic activation on saliva flow rate can be made, as more than one parameter (sympathetic and parasympathetic activity) has an effect on the outcome measure (saliva flow rate).

The results of this study do not contradict the suggestion of $\alpha$-amylase being used as a marker of sympathetic activation. ${ }^{32}$ As $\alpha$-amylase is an enzyme fulfilling functions such as breaking down starch or supporting the immune system by neutralising pathogens, ${ }^{32,33}$ it is not to be expected that impaired sympathetic function would result in a complete suppression of this enzyme. Consequently, a baseline level of $\alpha$-amylase could be measured throughout the experiments, however, any exercise-related increases were not observed, being in line with the theory of an altered sympathetic function in the participants of this study.

Although earlier work in our laboratory investigated the effects of strenuous exercise on immune function in tetraplegic athletes, one potential downfall of this previous investigation was that exercise intensity was chosen as a percentage of peak oxygen uptake, ${ }^{16}$ which may have caused differing, and not necessarily maximal strain in all individuals. In the present study, all individuals were instructed to exercise at the maximum of their abilities, which, in able-bodied individuals, would cause a high degree of sympathetic activation, as sympathetic activation seems to increase as a function of muscle cell $\mathrm{pH}$ and exercise intensity. ${ }^{30}$

With regards to the present study, average $\mathrm{HR}_{\text {peak }}$ was higher when compared with the literature investigating tetraplegic individuals previously. ${ }^{34,35}$ It should be noted that the participants of this study comprised of a highly trained group, referring to the high weekly training volume and professional training structure of each individual, which is in contrast to these previous investigations. Even though speculative, it is therefore possible that long-term elite training results in physiological adaptations enabling to access larger parts of the sympathetic nervous system. This may result in greater sympathetic activity, which may in turn increase $\mathrm{HR}_{\text {peak }}$. This theory is supported by a previous investigation in tetraplegic elite athletes, where a similar average $H_{\text {peak }}$ to the present study was observed. ${ }^{36}$ However, it must be noted that different protocols were used to determine $\mathrm{HR}_{\text {peak }}$ in previous investigations, ${ }^{34,35}$ which may have influenced physiological responses.

A further fact underpinning the importance of transferring laboratory-based findings into the field is the elevated $\mathrm{BLa}_{\text {peak }}$ measured during the court training sessions when compared with laboratory data in populations of the same elite nature as the one in the present study, where average $\mathrm{BLa}_{\text {peak }}$ of $4-5 \mathrm{mmoll}^{-1}$ was measured. ${ }^{37,38}$ We appreciate that different BLa analysers are used for this comparison; however, the large differences in $\mathrm{BLa}_{\text {peak }}$ suggest these were most likely 'real' differences, even more as the lactate analyser used in the present study compares well to other laboratorybased systems. ${ }^{39}$ Even though all BLa measurements were taken immediately after a high degree of exertion and from elite athletes, ${ }^{38}$ the protocols used in the laboratory previously (notably peak tests to exhaustion) may not have been optimal to exhaust the potential of the anaerobic system in tetraplegic athletes. In contrast, exercising in their normal sporting environment provided optimal conditions, stressing the anaerobic system to a higher degree. We can only assume that similar principles potentially apply to other physiological processes, such as the government of sympathetic activity. Therefore, a field environment may be more suitable to generate the greatest stress on the sympathetic system. It is worth noting that the 
magnitude of $\mathrm{BLa}_{\text {peak }}$ measured following court training sessions compares well to existing literature. ${ }^{34}$ Interestingly, despite the small active muscle mass in tetraplegic athletes, $\mathrm{BLa}_{\text {peak }}$ values even compare with measurements derived after highly strenuous cycling exercise. ${ }^{23}$ We suggest the elite athlete nature of our participants and a potentially decreased total blood volume ${ }^{40}$ as most likely causes for these considerably high values.

On a final note, the distance covered during both training sessions compares well to distances measured during actual game play in wheelchair rugby. ${ }^{41}$ Measurement of this type of data can be used to confirm the ecological validity, and may further be used to help quantifying the exercise load of a training session. For future studies, we suggest collecting velocity and/or acceleration data to gain further insight into the dynamics and strain of wheelchair rugby training sessions and game play.

\section{LIMITATIONS}

It should be noted that because of the yearly planning of the wheelchair athletes tested, it was not possible to conduct standard laboratory tests for the determination of peak oxygen uptake. However, if feasible in future studies, measuring objective data of aerobic capacity would facilitate comparison of the fitness status of the participants with existing literature.

It must further be appreciated that no functional tests have been carried out to assess whether participants had a functional complete lesion of the sympathetic nervous system, even though this is highly likely, as the spinal cord injury of every athlete was motor and sensory complete. Assuming complete lesions of the sympathetic nervous system, this opens an interesting discussion, as our results suggest that individuals with a spinal cord injury can compensate lost centrally mediated function by peripheral adaptations. We therefore suggest this area to be followed up on in future investigations.

Finally, it should be noted that some data on sIgA metabolism in the literature are conflicting in able-bodied populations, and a number of studies have shown no decrease or even increases in SIgA secretion rate following strenuous exercise. ${ }^{1,23}$ However, all-out exercise protocols tend to give more consistent results, that is, depression of the mucosal immune function. ${ }^{6-8}$ Still, future studies should acknowledge the influence of exercise modalities on the mucosal immune response, such as intensity, duration, or resting state of the participant.

\section{CONCLUSION}

Acute bouts of highly strenuous exercise do not have negative impacts on the mucosal immune response in tetraplegic athletes, nor do they influence the production of $\alpha$-amylase, a marker of sympathetic nervous activity. This contrasts responses previously observed in ablebodied athletes. The disruption of the sympathetic nervous system may prevent the downregulation of sIgA secretion rate following intense exercise. However, the observed decreases in saliva flow rate and the relatively high heart rate observed during exercise may be attributed to the contribution of changing sympathetic activity, which may be qualitatively altered, but in parts still be functioning.

\section{DATA ARCHIVING}

There were no data to deposit.

\section{CONFLICT OF INTEREST}

The authors declare no conflict of interest.

\section{ACKNOWLEDGEMENTS}

We thank Tom Paulson and Dr Barry Mason for their expertise and contribution during data collection, the support from Dan Howells, the Great Britain Wheelchair Rugby Ltd and Matt Bramhall from the English Institute of Sport for their kind cooperation. Appreciation is also extended to all athletes who volunteered to participate in this study. No direct funding was received for this work, other than the support from the corresponding institution.

1 Bishop NC, Gleeson M. Acute and chronic effects of exercise on markers of mucosal immunity. Front Biosci 2009; 14: 4444-4456.

2 Woof JM, Kerr MA. The function of immunoglobulin A in immunity. J Pathol 2006; 208: 270-282.

3 FahIman MM, Engels HJ. Mucosal IgA and URTI in American College Football Players: a year longitudinal study. Med Sci Sports Exerc 2005; 37: 374-380.

4 Neville V, Gleeson M, Folland JP. Salivary IgA as a risk factor for upper respiratory infections in elite professional athletes. Med Sci Sports Exerc 2008; 40: 1228-1236.

5 Proctor GB, Carpenter GH. Regulation of Salivary gland function by autonomic nerves. Auton Neurosci 2007; 133: 3-18.

6 Mackinnon LT, Ginn E, Seymour GJ. Decreased salivary immunoglobulin a secretion rate after intense interval exercise in Elite Kayakers. Eur J Appl Physiol Occup Physiol 1993; 67: 180-184.

7 Walsh NP, Bishop NC, Blackwell J, Wierzbicki SG, Montague JC. Salivary IgA response to prolonged exercise in a cold environment in trained cyclists. Med Sci Sports Exerc 2002; 34: 1632-1637.

8 Nieman DC, Henson DA, Fagoaga OR, Utter AC, Vinci DM, Davis JM et al. Change in salivary IgA following a competitive marathon race. Int J Sports Med 2002; 23: 69-75.

9 Krassioukov A. Autonomic function following cervical spinal cord injury. Respir Physiol Neurobiol 2009; 169: 157-164.

10 Corbett JL, Frankel HL, Harris PJ. Cardiovascular reflex responses to cutaneous and visceral stimuli in spinal man. J Physiol 1971; 215: 395-409.

11 Campagnolo DI, Dixon D, Schwartz J, Bartlett JA, Keller SE. Altered innate immunity following spinal cord injury. Spinal Cord 2008; 46: 477-481.

12 Riegger T, Conrad S, Schluesener HJ, Kaps HP, Badke A, Baron C et al. Immune depression syndrome following human spinal cord injury ( $\mathrm{SCl}$ ): a pilot study. Neuroscience 2009; 158: 1194-1199.

13 Brown R, DiMarco AF, Hoit JD, Garshick E. Respiratory dysfunction and management in spinal cord injury. Respir Care 2006; 51: 853-870.

14 Stjernberg L, Blumberg H, Wallin BG. Sympathetic activity in man after spinal cord injury. Outflow to muscle below the lesion. Brain 1986; 109: 695-715.

15 Schmid A, Schmidt-Trucksass A, Huonker M, Konig D, Eisenbarth I, Sauerwein $\mathrm{H}$ et al. Catecholamines response of high performance wheelchair athletes at rest and during exercise with autonomic dysreflexia. Int J Sports Med 2001; 22: 2-7.

16 Leicht CA, Bishop NC, Goosey-Tolfrey VL. Mucosal immune responses to treadmill exercise in elite wheelchair athletes. Med Sci Sports Exerc 2011; 43: 1414-1421.

17 International Wheelchair Rugby Federation. IWRF www.iwrf.com, retrieved 27 January 2012.

18 Borg GA. Psychophysical bases of perceived exertion. Med Sci Sports Exerc 1982; 14 377-381.

19 Sporner ML, Grindle GG, Kelleher A, Teodorski EE, Cooper R, Cooper RA. Quantification of activity during wheelchair basketball and rugby at the National Veterans Wheelchair Games: a pilot study. Prosthet Orthot Int 2009; 33: 210-217.

20 Cole AS, Eastoe JE. Biochemistry and Oral Biology, 2nd edn. Wright: London, 1988, pp 476-477.

21 Chicharro JL, Lucia A, Perez M, Vaquero AF, Urena R. Saliva composition and exercise. Sports Med 1998; 26: 17-27.

22 Chatterton Jr RT, Vogelsong KM, Lu YC, Ellman AB, Hudgens GA. Salivary Alphaamylase as a measure of endogenous adrenergic activity. Clin Physiol 1996; 16: 433-448.

23 Walsh NP, Blannin AK, Clark AM, Cook L, Robson PJ, Gleeson M. The effects of highintensity intermittent exercise on saliva IgA, total protein and alpha-amylase. J Sports Sci 1999; 17: 129-134.

24 Klokker M, Mohr T, Kjaer M, Galbo H, Pedersen BK. The natural killer cell response to exercise in spinal cord injured individuals. Eur J Appl Physiol Occup Physiol 1998; 79: 106-109.

25 Oliver SJ, Laing SJ, Wilson S, Bilzon JL, Walters R, Walsh NP. Salivary immunoglobulin a response at rest and after exercise following a $48 \mathrm{~h}$ period of fluid and/or energy restriction. Br J Nutr 2007; 97: 1109-1116.

26 Walsh NP, Laing SJ, Oliver SJ, Montague JC, Walters R, Bilzon JL. Saliva parameters as potential indices of hydration status during acute dehydration. Med Sci Sports Exerc 2004; 36: 1535-1542.

27 Karlsson AK, Friberg P, Lonnroth P, Sullivan L, Elam M. Regional sympathetic function in high spinal cord injury during mental stress and autonomic dysreflexia. Brain 1998; 121: 1711-1719.

28 Bloomfield SA, Jackson RD, Mysiw WJ. Catecholamine response to exercise and training in individuals with spinal cord injury. Med Sci Sports Exerc 1994; 26 1213-1219. 
29 Vissing J, Wilson LB, Mitchell JH, Victor RG. Static muscle contraction reflexly increases adrenal sympathetic nerve activity in rats. Am J Physiol 1991; 261: R1307-R1312.

30 Victor RG, Bertocci LA, Pryor SL, Nunnally RL. Sympathetic nerve discharge is coupled to muscle cell pH during exercise in humans. J Clin Invest 1988; 82: 1301-1305.

31 Arnold JM, Feng QP, Delaney GA, Teasell RW. Autonomic dysreflexia in tetraplegic patients: evidence for alpha-adrenoceptor hyper-responsiveness. Clin Auton Res 1995, 5: 267-270.

32 Nater UM, Rohleder N. Salivary alpha-amylase as a non-invasive biomarker for the sympathetic nervous system: current state of research. Psychoneuroendocrinology 2009; 34: 486-496.

33 Scannapieco FA, Solomon L, Wadenya RO. Emergence in human dental plaque and host distribution of amylase-binding streptococci. J Dent Res 1994; 73: 1627-1635.

34 Bhambhani YN, Holland LJ, Eriksson P, Steadward RD. Physiological responses during wheelchair racing in quadriplegics and paraplegics. Paraplegia 1994; 32: 253-260.
35 Coutts KD, Rhodes EC, McKenzie DC. Maximal exercise responses of tetraplegics and paraplegics. J Appl Physiol 1983; 55: 479-482.

36 Goosey-Tolfrey V, Castle P, Webborn N. Aerobic capacity and peak power output of elite quadriplegic games players. Br J Sports Med 2006; 40: 684-687.

37 Abel T, Peters C, Platen P. Performance profile and health assessment of elite quad rugby players. Eur J Sport Sci 2003; 3: 1-7.

38 Leicht CA, Bishop NC, Goosey-Tolfrey VL. Submaximal exercise responses in tetraplegic, paraplegic and non spinal cord injured elite wheelchair athletes. Scand J Med Sci Sports 2011 (e-pub ahead of print 23 May 2011; doi:10.1111/j.16000838.2011.01328.x).

39 Pyne DB, Boston T, Martin DT, Logan A. Evaluation of the lactate pro blood lactate analyser. Eur J Appl Physiol 2000; 82: 112-116.

40 Houtman S, Oeseburg B, Hopman MT. Blood volume and hemoglobin after spinal cord injury. Am J Phys Med Rehabil 2000; 79: 260-265.

41 Sarro KJ, Misuta MS, Burkett B, Malone LA, Barros RM. Tracking of wheelchair rugby players in the 2008 Demolition Derby Final. J Sports Sci 2010; 28: 193-200. 